\title{
HVDC Circuit Breakers for HVDC Grids
}

\author{
A. Etxegarai, D.M. Larruskain, O. Abarrategi, P. Eguia, G. Buigues \\ Department of Electrical Engineering, \\ University of the Basque Country UPV/EHU \\ Bilbao, Spain
}

\begin{abstract}
HVDC grids are evolving into VSC-HVDC multiterminal systems that are more demanding than point-topoint links. The protection of HVDC grids from DC faults is particularly challenging, essentially because of the absence of natural current zero crossing and of the required short operation time. Therefore, the lack of circuit breakers in the DC side when a DC fault occurs takes too long and can even lead to outages. This paper presents different possible CB topologies in order to comply with HVDC grid requirements, and analyses their use in VSC-HVDC multiterminal grids.
\end{abstract}

Keywords-Circuit breaker, DC fault, HVDC grid, protection.

\section{INTRODUCTION}

Direct current (DC), unlike alternating current (AC), does not cross naturally current zero. This is a huge challenge for DC current interruption, which must be performed at current zero. This way, HVDC circuit breakers (CB) must create artificially a current zero in order to interrupt DC current [1][3]. Considering the high ratings of HVDC systems, this becomes significantly challenging. Moreover, future HVDC grid requirements are expected to increase the demanded ratings for $\mathrm{HVDC} \mathrm{CBs}$.

Even though the interrupted current must be zero, in the remaining system the current might still be considerable. In that sense, the limiting inductances in the circuit store a substantial amount of energy in their magnetic field [4]. Therefore, the related energy stored in the circuit must be given consideration when sizing the $\mathrm{CB}$. On account of that, the HVDC CB must have a large capability for dissipating the energy stored in the circuit [2][3].

Adding complexity to the abovementioned difficulties, the operating time of circuit breakers is extremely reduced. The protection system should operate in less than $10 \mathrm{~ms}$ to protect the system with reliability [5]-[8]. In that reduced period of time, faults must be detected, located and interrupted.

Therefore, the requirements for $\mathrm{DC}$ and $\mathrm{AC} \mathrm{CBs}$ are remarkably different. The manufacturing of HVDC $\mathrm{CBs}$ has been extremely complex and as a result, the first commercial devices have been recently developed, at high expense.

Voltage Source Converter (VSC) systems have been traditionally protected in the $\mathrm{AC}$ side with $\mathrm{AC}$ CBs. This strategy is suitable for protecting point-to-point links and occasionally even for multiterminal systems with a few converter stations, but not for large grids. Consequently, considering the demanding requirements for the reliable protection of large HVDC grids, the availability of reliable and robust HVDC $\mathrm{CBs}$ will be imperative for the development of those grids, preferably at a reasonable price.

This paper deals with the role of HVDC CBs in HVDC grids. This way, the requirements for the protection of HVDC grids are discussed. Then, the main topologies of HVDC CBs are analysed and compared. Finally, the main features of the protection switchgear of existing multiterminal systems are reviewed.

\section{HVDC GRID REQUIREMENTS}

A meshed HVDC grid is defined in CIGRE as "a system consisting of at least three converter stations and which includes at least one mesh formed by transmission lines" [9].

The main objectives of the protection of any grid, both in $\mathrm{AC}$ and DC systems, are the assurance of human safety, the clearance of faults and minimizing the impact of the fault on the whole system, particularly on all components [10]

This way, the main features of any grid protection system are detailed:

- Sensitivity: Precise detection and clearance of all faults.

- Selectivity: Discrimination between normal operation and fault condition. The grid is divided in several zones with the objective that the protection system should just operate in case the fault is located in its own protection zone.

- Speed: Faults must be cleared while they are below the interruption capability of the circuit breakers and before causing any damage to the equipment. This requirement is extremely demanding for DC grids, as the available time is below $10 \mathrm{~ms}$.

- Reliability: The operation must be safe, i.e., a backup protection system is required in case the failure or inability of the primary protection system to operate.

- Robustness: Faults must be discriminated from any other operation event.

- Stability: After fault clearing, the grid must be stable in a reasonable period of time.

The abovementioned features are applicable for $\mathrm{AC}$ and DC grids. Nevertheless, DC grids have more demanding constraints than AC grids. When a DC fault appears in a DC system, the voltage collapses almost instantaneously and the small impedance of the system leads to a current rise up to very high values.

HVDC grids are usually based on VSC converters, which are highly sensitive to overcurrents. The main components of those converters are IGBTs, which can usually withstand just twice the rated current to remain in the safe operating area.

Highly meshed grids will increase these difficulties. The total DC system impedance will be reduced, causing faster DC voltage collapses. Besides, fault currents will increase due to higher line discharge currents as well as the contribution from multiple sources. Therefore, higher pole-toground and pole-to-pole fault currents can be expected [11][12]. 
The DC grid protection also influences the control of the DC voltage. In case of fault, the protection system may block or disconnect some converter stations which can limit the DC voltage control [10].

Large protection zones have a high number of converters interconnected, and therefore, they will require to have selectivity using HVDC CBs [9]. Even though CBs are highly expensive, they will deeply improve the reliability of HVDC grids. This way, within each protective zone, fault selectivity, protection co-ordination and minimum breaking, clearance and restoration times must be defined [10].

HVDC grids require protection strategies, which are outlined by the selectivity of the protection devices and the used method for interrupting and isolating DC faults. One grid can combine different strategies. Next, the three main fault clearing strategies are described [13]:

- Non-selective fault clearing: The complete HVDC grid is considered as one protection zone. In case of fault, the affected line is located but the complete grid is de-energized. The affected line is isolated and finally the non affected grid is re-energized. This strategy is just feasible for small grids.

- Full selective fault clearing: The fault is detected and located, and only the affected part of the line is disconnected, whilst the remaining elements keep on operating.

- Partial selective fault clearing: It is a mixture of the other two strategies.

Besides, for a reliable operation of HVDC grids, a grid planning and operation code must be stablished. That grid code must define fault scenarios where the affected part of the system should either remain connected or otherwise be safely disconnected from the grid [10].

In addition, it will be required to establish the proportion and duration of fault currents that could take place, depending on the grid topology. Furthermore, the time for interrupting faults and to insulate the affected devices from the grid must be defined. Those time requirements will influence the selected protection strategies.

Finally, the converters that are incorporated to the grid must assure that they will operate safely.

\section{CIRCUIT BREAKER TOPOLOGIES}

\section{A. Mechanical Circuit Breakers}

The operating principle of mechanical CBs is based on the generation of current zero with a resonant circuit [2][9]. Mechanical CBs are composed of three parallel paths as shown in the typical layout represented in Fig. 1. The nominal current path consists on a low-resistance mechanical interrupter, such as an AC vacuum interrupter [4]. In the commutation path there is a LC resonant circuit, different circuit topologies can be found in the state of art [9]. Finally, the energy absorption path consists of banks of surge arresters.

There are two main concepts for mechanical CBs that are analysed in the following subsections.

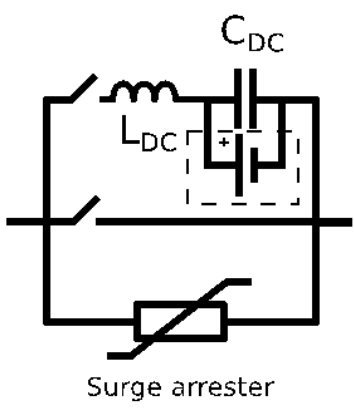

Fig. 1. Topology of a mechanical CB.

\section{1) Passive Oscillation Circuit Breakers}

The regular layout of a passive oscillation $\mathrm{CB}$ is depicted in Fig. 1, with the absence of the DC power source inside the dotted rectangle which is located in the commutation branch.

When the contacts of the interrupter in the main path open, an arc is stablished. The arc presents a voltage-current non-linear relationship, in such a manner that a voltage rise results in a diminished current. This way, the naturally occurring arc voltage variation initiates a current oscillation that increases the amplitude, between the arc and the LC circuit in the commutation path. In case the created swinging current exceeds the HVDC system current, a current zero appears. At that moment, the switch in the commutation path can open and interrupt the circuit. The remaining current charges the capacitor $\mathrm{C}_{\mathrm{DC}}$ and when the threshold voltage of the surge arrester in the third path is exceeded, the surge arrester bank operates and dissipates the energy.

Higher oscillation frequencies lead to reduced interruption times at the expense of having a higher differential current, which is more challenging to interrupt. Besides, the time required for this process is the largest of all concepts.

\section{2) Active Current Injection Circuit Breakers}

Active current injection $\mathrm{CBs}$ are a progress of the previously analysed passive oscillation CBs. Therefore, an active component is added to the previous concept topology, in order to pre-charge the capacitor $\mathrm{C}_{\mathrm{DC}}$. In the mechanical CB depicted in Fig. 1, the active element is illustrated inside the dotted rectangle and it consists on a DC source that precharges the capacitor $\mathrm{C}_{\mathrm{DC}}$. This way, when the arc is initiated, the oscillation emerges immediately and as a result, the interruption time is shorter than in the passive $\mathrm{CB}$. For this reason, active $\mathrm{CBs}$ are more suitable for being implemented in HVDC grids.

Fig. 2 shows the interruption of a fault current with an active injection $\mathrm{CB}$ on a $400 \mathrm{kV}$ system. The fault is applied at $2 \mathrm{~s}$. The current in the main branch increases quickly as a consequence of the fault. $5 \mathrm{~ms}$ after fault inception, the current is directed to the commutation branch, being the peak fault current $22.8 \mathrm{kA}$. When the arc is interrupted, the current is directed to the energy absorption path, where it decreases and it is finally entirely interrupted. The total interruption time is $17 \mathrm{~ms}$. The fundamental feature of the CB is the time demanded for the transfer of fault current to the commutation path, which defines the interruption capability of the device. In this case, it amounts to $20.2 \mathrm{kA}$ at $5 \mathrm{~ms}$ [4]. 


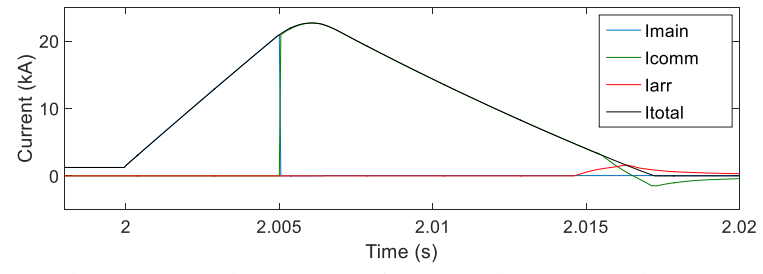

Fig. 2. Interruption process of current with a mechanical CB.

\section{B. Solid State Circuit Breakers}

Solid state CBs are based on power electronic devices for interrupting the current. Fig. 3 shows a typical topology. As it can be observed, solid state CBs consists of only two branches. In the main current branch there are IGBT stacks and the energy absorption branch is composed of surge arrester banks. The number of IGBTs should be selected according to the $\mathrm{CB}$ voltage and current rating.

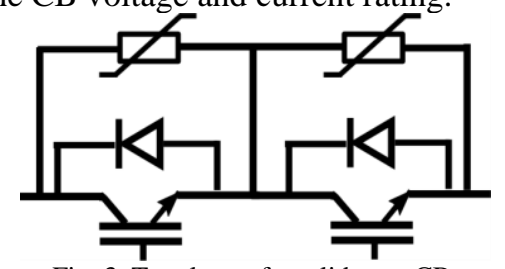

Fig. 3. Topology of a solid state CB.

IGBTs can commute in a few microseconds, and accordingly, the current is commuted to the energy absorption path really fast. The short operation time is, indeed, the most characteristic feature of solid state CBs. Besides, IGBTs, which are connected permanently in the main current path, produce losses that are excessive, considering the total operational life of the CB. For that reason, solid state $\mathrm{CBs}$ are not likely to be used in HVDC grids.

In Fig. 4, the interruption process of a solid state $\mathrm{CB}$ is sown. The operation of the IGBTs is extremely fast. Therefore, the current is derived to the energy dissipation path in the order of microseconds. That fast commutation involves that the fault time has a shorter time to increase and therefore, the peak fault current that the CB must interrupt is smaller. In this case, the peak fault current is $2.2 \mathrm{kA}$, which is remarkably lower than in the case of the mechanical $\mathrm{CB}$. The current is finally interrupted in an interruption time lower than $1 \mathrm{~ms}$.

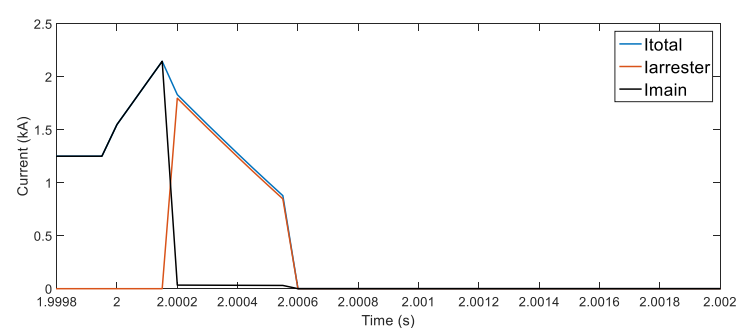

Fig. 4. Interruption process of current with a solid state CB.

\section{Hybrid Circuit Breakers}

Hybrid CBs integrate the features of mechanical and solid state CBs [9][14]. The layout of a hybrid CB is shown in Fig. 5 and the operation is depicted in Fig. 6. The main current path is composed of a low-resistance ultrafast mechanical switch and of a small IGBT that is used as commutation switch to direct the current into the commutation path in case of fault. This procedure makes possible the opening of the ultrafast switch. There are IGBT stacks in the second path for interrupting the current by commutating this current to the last parallel path. Finally, the surge arrester banks in the third path dissipate the energy of the circuit.

The interruption process shows that the fast operation of the fast mechanical switch is below $1 \mathrm{~ms}$ and the current remains in the commutation path until it is derived to the energy absorption path, at instant $2.2 \mathrm{~ms}$. With this topology, the maximum fault current is $10 \mathrm{kA}$. The total interruption time is $17 \mathrm{~ms}$, which can be reduced if required.

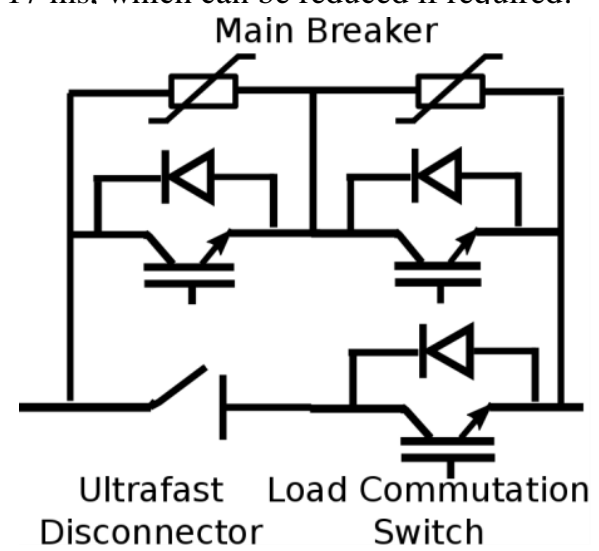

Fig. 5. Topology of a hybrid CB.

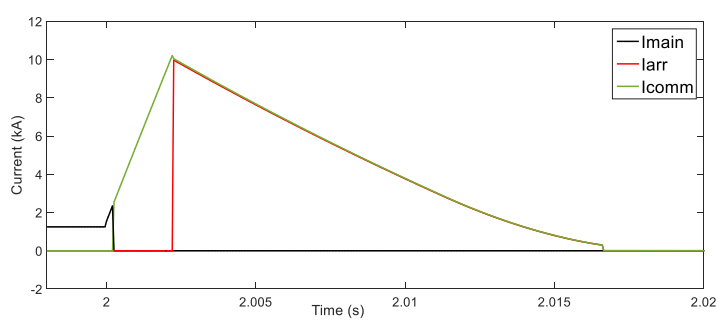

Fig. 6. Interruption process of current with a hybrid CB.

\section{Comparison of HVDC Circuit Breaker concepts}

In this section, the features of the main topologies analysed so far are discussed and compared according to the literature. However, note that those figures may improve in the future according to the current high interest on the development of HVDC CBs and the considerable effort that is, accordingly, being made.

Thus, the interruption time, on-state losses, voltage and current rating, internal commutation time, losses, costs and maintenance are shown in table I for the different concepts. In this table, mechanical $\mathrm{CBs}$ are represented by active current injection CBs.

TABLE I. FEATURES OF CB TOPOLOGIES [9][14][15][19].
\begin{tabular}{|l|c|c|c|}
\hline \multicolumn{1}{|c|}{ Feature } & $\begin{array}{c}\text { Mechanical } \\
\text { CB }\end{array}$ & $\begin{array}{c}\text { Solid } \\
\text { State CB }\end{array}$ & $\begin{array}{c}\text { Hybrid } \\
\text { CB }\end{array}$ \\
\hline $\begin{array}{l}\text { Interruption capability } \\
(\mathrm{kA})\end{array}$ & $2-16$ & 19 & 26 \\
\hline Voltage rating (kV) & $<400$ & 132 & 500 \\
\hline $\begin{array}{l}\text { Rate of rise of fault } \\
\text { current (kA/ms) }\end{array}$ & $1.6-2$ & 47 & $2.9-6.7$ \\
\hline Internal current & $<5-8$ & 0.4 & $2-3$ \\
\hline
\end{tabular}




\begin{tabular}{|l|c|c|c|}
\hline commutation time (ms) & & & \\
\hline On-state losses & Negligible & High & Low \\
\hline Installation Costs & Low & High & High \\
\hline Maintenance & Required & Low & Required \\
\hline
\end{tabular}

\section{HVDC CIRCUIT BREAKERS INSTALLED IN HVDC MULTITERMINAL SYSTEMS}

Nowadays there are no real HVDC meshed grids in operation. The first commissioned multiterminal HVDC (MTDC) systems where based in Line Commutated Converter (LCC) technology. In those current-fed systems the power flow is reversed by changing the polarity of the voltage, while the current is constant. The main examples of the pioneering MTDC systems are the hereinafter quoted [16][17]:

- Sardinia - Corsica - Italy (SACOI): It is a radial MTDC with three terminals to connect Sardinia and Corsica to mainland Italy. It was commissioned in 1967 and 1986. Now it is close to the end of its lifetime and there is a project to replace it.

- The Pacific intertie was initially commissioned in 1970 with just two terminals to transmit the major hydropower resources from the Columbia River in the north-western United States to Los Angeles. Besides, it has been upgraded several times and now it has four bipolar terminals in parallel.

- Québec - New England (New England Hydro): commissioned in the beginning of the 1990s to reinforce the existing $\mathrm{AC}$ lines between these regions of Canada and USA. It is a radial MTDC with three terminals: Radisson. Nicolet and Sandy Pond.

The main features of these systems are summarized in Table II [16][17].

TABLE II. MAIN SPECIFICATIONS OF VSC BASED MTDC

\begin{tabular}{|c|c|c|c|}
\hline Feature & SACOI & Pacific Intertie & $\begin{array}{c}\text { New England } \\
\text { Hydro }\end{array}$ \\
\hline Terminals & 3 & 4 & 3 \\
\hline $\begin{array}{c}\text { DC } \\
\text { voltage }\end{array}$ & $\pm 200 \mathrm{kV}$ & $\pm 560 \mathrm{kV}$ & $\pm 450 \mathrm{kV}$ \\
\hline Power & $450 \mathrm{MW}$ & $3800 \mathrm{MW}$ & $2250 \mathrm{MW}$ \\
\hline $\begin{array}{c}\text { Total } \\
\text { length }\end{array}$ & $406 \mathrm{~km}$ & $1360 \mathrm{~km}$ & $1480 \mathrm{~km}$ \\
\hline
\end{tabular}

With the development of VSC technology, the design of MTDC systems has been directed towards this new technology due to its inherent advantages. Among others, with VSC systems, it is possible to reverse the power flow changing the polarity of the current while the voltage is kept constant. This concept is similar to the one of AC grids. Nevertheless, the protection of these systems is still a major obstacle for the development of HVDC grids.

Recently, a number of VSC based MTDC systems have been commissioned, while several projects are in planning or construction phase [16]. Following, the most representative of these installations are reviewed:
- Nan'ao (2013): The first commissioned MTDC system based on modular multi-level converter (MMC) technology. The configuration is a symmetrical monopole with three terminals: Jinniu, Qing'ao and Sucheng. It is projected to construct a second stage with the connection of a fourth terminal [16][18].

This link connects Nan'ao island to mainland China with the objective of injecting the wind power generated in the island into the power system. There are two $110 \mathrm{kV}$ AC cables that connect the island. Thus, the three links operate in parallel. Nevertheless, it is possible to decouple them. The system presents DC disconnecting switches [18].

The system was initially protected from the AC side, with AC CBs for interrupting DC faults. This way, in case of DC faults, the converters were blocked and AC CBs interrupted the faults. Therefore, the required operation time for clearing DC faults was certainly high. Besides, the installation had the minimum initial outlay as well as minimal power losses. In 2017 three mechanical HVDC CBs were installed [4].

- Zhoushan (2014): The MTDC system connects five islands to mainland China. The Zhoushan islands were initially interconnected with mainland through two $220 \mathrm{kV}$ AC lines and three $110 \mathrm{kV}$ lines.

The major reasons for choosing VSC technology were the small footprint and the suitability of the technology for wind power evacuation, as well as for reinforcing the weak power system of the islands.

Originally, the MTDC system was protected with AC CBs but there were problems with the large operation times and also with the disconnection of the complete system for clearing a DC fault [19]. In fact, in the first two years of operation, nine forced outages took place, with the complete disconnection of the five terminals. In order to solve partially those hurdles, while increasing the reliability and availability of the system, two hybrid HVDC CBs were installed in Dinghai as well as a fast damping restoration apparatus in each terminal [20].

The hybrid CB consisted of four groups of $50 \mathrm{kV}$ power electronic modules, three groups of fast mechanical switches, one group of auxiliary breakers and four groups of lightning arrester units [4]. The HVDC breaker developed for the Zhoushan system was intented to be used as a pilot project for the $\mathrm{CB}$ of the Zhangbei MTDC system [16].

- Zhangbei: a four-terminal onshore MTDC system is under construction in China for transmitting renewable energies from Hebei province to Beijing. This way, Zhangbei and Kangbao terminals are sending wind power and Fengning terminal is connected to a pumped-storage hydraulic power plant that can adjust the variation of the wind power generation. The system presents a bipolar configuration with a metallic return line. The long transmission system is composed of overhead lines, and therefore, HVDC CBs are required at both ends of 
each line. A $500 \mathrm{kV}$ HVDC CB prototype has been developed in 2018 [4].

Table III summarizes the main specifications of these systems. The test performed with the CBs include the breaking current, peak transient recovery voltage (TRV) and the required breaking time.

TABLE III. MAIN SPECIFICATIONS OF VSC BASED MTDC PROJECTS [18]-[21].

\begin{tabular}{|c|c|c|c|}
\hline Feature & Nan'ao & Zhoushan & Zhangbei \\
\hline Terminals & 3 & 5 & 4 \\
\hline $\begin{array}{c}\mathrm{DC} \\
\text { voltage }\end{array}$ & $\pm 160 \mathrm{kV}$ & $\pm 200 \mathrm{kV}$ & $\pm 500 \mathrm{kV}$ \\
\hline $\begin{array}{l}\text { Power } \\
\text { (MW) }\end{array}$ & $\begin{array}{l}\text { Sucheng: } 200 \\
\text { Jinniu: } 100 \\
\text { Qing'ao: } 50\end{array}$ & $\begin{array}{c}\text { Zhoushan: } 400 \\
\text { Daishan: } 300 \\
\text { Qushan: } 100 \\
\text { Yangshan: } 100 \\
\text { Sijiao: } 100\end{array}$ & $\begin{array}{c}\text { Beijing: } 3000 \\
\text { Zhangbei: } 3000 \\
\text { Kangbao: } 1500 \\
\text { Fengning: } 1500\end{array}$ \\
\hline $\begin{array}{l}\text { Cable } \\
\text { length }\end{array}$ & $\begin{array}{c}40.7 \mathrm{~km} \\
\text { overhead - cable }\end{array}$ & $\begin{array}{c}141.5 \mathrm{~km} \\
\text { submarine cable }\end{array}$ & $\begin{array}{c}648 \mathrm{~km} \\
\text { overhead }\end{array}$ \\
\hline $\begin{array}{c}\mathrm{CB} \\
\text { features }\end{array}$ & $\begin{array}{c}\text { Mechanical CB } \\
\text { Rated voltage: } \\
160 \mathrm{kV}\end{array}$ & $\begin{array}{c}\text { Hybrid CB } \\
\text { Rated voltage: } \\
200 \mathrm{kV} \\
\text { Max. operat. } \\
\text { Current: } 1.2 \mathrm{kA} \\
\text { Max. breaking } \\
\text { current: } 15 \mathrm{kA} \\
\text { Breaking time: } \\
3 \mathrm{~ms}\end{array}$ & $\begin{array}{c}\text { Hybrid CB } \\
\text { Rated voltage: } \\
500 \mathrm{kV}\end{array}$ \\
\hline CB Test & $\begin{array}{c}\text { Forward current: } \\
9.2 \mathrm{kA} \\
\text { TRV: } 272 \mathrm{kV} \\
\text { Breaking time: } \\
3.9 \mathrm{~ms} \\
\text { Reverse Current: } \\
9.2 \mathrm{kA} \\
\text { TRV: } 262 \mathrm{kV} \\
\text { Breaking time: } \\
4.6 \mathrm{~ms}\end{array}$ & $\begin{array}{c}\text { Forward } \\
\text { current: } 15 \mathrm{kA} \\
\text { Breaking time: } \\
3 \mathrm{~ms} \\
\text { TRV: } 73 \mathrm{kV} \\
\text { Arrester } \\
\text { absorbed } \\
\text { energy: } 27 \mathrm{~kJ}\end{array}$ & $\begin{array}{l}\text { Current: } 26 \mathrm{kA} \\
\text { Breaking time: } \\
2.6 \mathrm{~ms} \\
\text { TRV: } 810 \mathrm{kV}\end{array}$ \\
\hline
\end{tabular}

\section{CONCLUSIONS}

HVDC grids will require HVDC CBs for a reliable operation. This paper first establishes the characteristics that a HVDC protection system has to have in order to fulfill the necessary requirements. Once the requirements have been specified, HVDC CB topologies that fulfill those requirements have been reviewed. Thus, mechanical, solid state and hybrid CBs have been analysed and compared. The study presented hereby stands out that whilst mechanical CBs have lower onstate losses and installation costs, their internal current commutation times are higher. These features are improved in both solid state and hybrid CB. On the other hand, solid state $\mathrm{CBs}$ cause very high losses.

When applied to multiterminal VSC-HVDC systems, there is an increasing trend to introduce $\mathrm{CBs}$ on the $\mathrm{DC}$ side, since installing them on the $\mathrm{AC}$ side increases excessively the DC fault clearing time and thus, may result in outages. Therefore, the preferred DC circuit breaker types are hybrid $\mathrm{CBs}$, although mechanical CBs have also been used.

As a conclusion, the transition from LCC-HVDC multiterminal systems to VSC-HVDC multiterminal systems will certainly require the implementation of $\mathrm{CBs}$ on the $\mathrm{DC}$ side in order to prevent outages during fault situations and to satisfy the DC protection requirements and specifications. The DC topologies will be selected depending on the characteristics and requirements of the particular system, since all available topologies offer different advantages and disadvantages. Hence, more research will necessarily have to be carried out in order to improve the existing CB solutions for DC faults.

\section{ACKNOWLEDGMENT}

The authors gratefully acknowledge the support from the Spanish Ministry of Economy, Industry and Competitiveness (project ENE2016-79145-R AEI/FEDER, UE), the Basque Government (GISEL research group IT1191-19), as well as from the University of the Basque Country UPV/EHU (research group funding GIU18/181)

\section{REFERENCES}

[1] W. Leterme, D. Van Hertem, "Classification of Fault Clearing Strategies for HVDC Grids" Cigré, Lund, 2015.

2] M. K. Bucher, C. M. Franck, "Fault Current Interruption in Multiterminal HVDC Networks," IEEE Transactions on Power Delivery, vol. 31, (1), pp. 87-95, 2016.

[3] W. Leterme et al, "Designing for High-Voltage dc Grid Protection: Fault Clearing Strategies and Protection Algorithms," IEEE Power and Energy Magazine, vol. 17, (3), pp. 73-81, 2019.

[4] D. Jovcic, G. Tang, H. Pang, "Adopting Circuit Breakers for HighVoltage dc Networks: Appropriating the Vast Advantages of dc Transmission Grids," IEEE Power and Energy Magazine, vol. 17, (3) pp. 82-93, 2019. . DOI: 10.1109/MPE.2019.2897408

[5] J. Descloux et al, "HVDC Meshed Grid: Control and Protection of Multi-terminal HVDC System," CIGRÉ Session Paris (Paper B4-308) pp. 10, 2012. Available: https://e-cigre.org/publication/B4-308_2012 hvdc-meshed-grid-control-and-protection-of-a-multi-terminal-hvdcsystem.

[6] M. Heidemann et al, "A systematic study on fault currents in multiterminal HVDC grids," in Cigré - Lund Symposium, Lund, Sweden, 2015, Available: http://publications.rwthaachen.de/record/478751.

[7] R. Li, L. Xu, "Review of DC fault protection for HVDC grids," vol. 7 , (2), 2018. . DOI: 10.1002/wene.278

[8] S. Le Blond et al, "Design of protection schemes for multi-terminal HVDC systems," Renewable and Sustainable Energy Reviews, vol. 56, pp. 965-974, 2016.

[9] CIGRÉ WG A3/B4.34, “ Technical requirements and specifications of state-of-the-art HVDC switching equipment”, 2017.

[10] CIGRÉ WG B4.56 "Guidelines for the preparation of connection agreements or grid codes for multi-terminal DC schemes and DC grids", 2016.

[11] M. Bucher, C. Franck, «Contribution of Fault Current Sources in Multiterminal HVDC Cable Networks", IEEE Transactions on Power Delivery, No. 28, Vol. 3, 2013, pp. 1796-1803.

[12] G. Chaffey, T. Green, "Reduced DC circuit breaker requirement on mixed converter HVDC networks", in IEEE PowerTech, Eindhoven, 2015.

[13] CIGRÉ WG B4.52, "HVDC Grid Feasibility Study," Cigré, 2013 Available: https://e-cigre.org/publication/533-hvdc-grid-feasibilitystudy.

[14] J. Häfner, B. Jacobson, "Proactive Hybrid HVDC Breakers-A key innovation for reliable HVDC grids", Bologna, CIGRÉ Symposium, 2011

[15] M. Larruskain, A. Etxegarai, A. Iturregi, O. Abarrategi, S. Apiñaniz, 'Superconducting circuit breaker concepts for the protection of HVDC systems', in 15th International Conference on AC and DC Power Transmission ACDC 2019, Coventry 2019.

[16] G. Buigues, V. Valverde, A. Etxegarai, P. Eguía, E. Torres, "Presen and future multiterminal HVDC systems: current status and forthcoming developments", in ICREPQ’17 Malaga, April, 2017.

[17] M. Häusler, "Multiterminal HVDC for High Power Transmission in Europe", in CEPEX99, Poznan Poland, March 1999. 
[18] H. Rao, "Architecture of Nan'ao multi-terminal VSC-HVDC system and its multi-functional control", CSEE Journal of Power and Energy Systems, vol. 1, pp. 9-18, 2015

[19] G. Tang, G. Wang, et al., "Research on Key Technology and Equipment for Zhangbei $500 \mathrm{kV}$ DC Grid", High Voltage Engineering, 2018, Vol. 44, Issue 7, pp. 2097-2106.

[20] "C-EPRI participates in the world's first dc circuit breaker project", May 2016

http://www.cepri.com.cn/release/details_66_759.htm
[21] Z. Zhang, X. Li, et al "Research and Development of $160 \mathrm{kV}$ UltraFast Mechanical HVDC Circuit Breaker", Dianwang Jishu/Power System Technology, vol. 41, Aug. 2017, pp 2417-2422. 